Supplement of Atmos. Chem. Phys. Discuss., 14, 13491-13527, 2014

http://www.atmos-chem-phys-discuss.net/acpd-14-13491-2014/

doi:10.5194/acpd-14-13491-2014-supplement

(C) Author(s) 2014. CC Attribution 3.0 License.

(c) (i)

Supplement of

\title{
Spatial variations and development of land use regression models of levoglucosan in four European study areas
}

\author{
A. Jedynska et al.
}

Correspondence to: A. Jedynska (aleksandra.jedynska@tno.nl) 


\section{Online supplement}

Table S1. Predictor variables with predefined variable names, units, defined buffer sizes, transformations of the predictor variables and directions of effect.

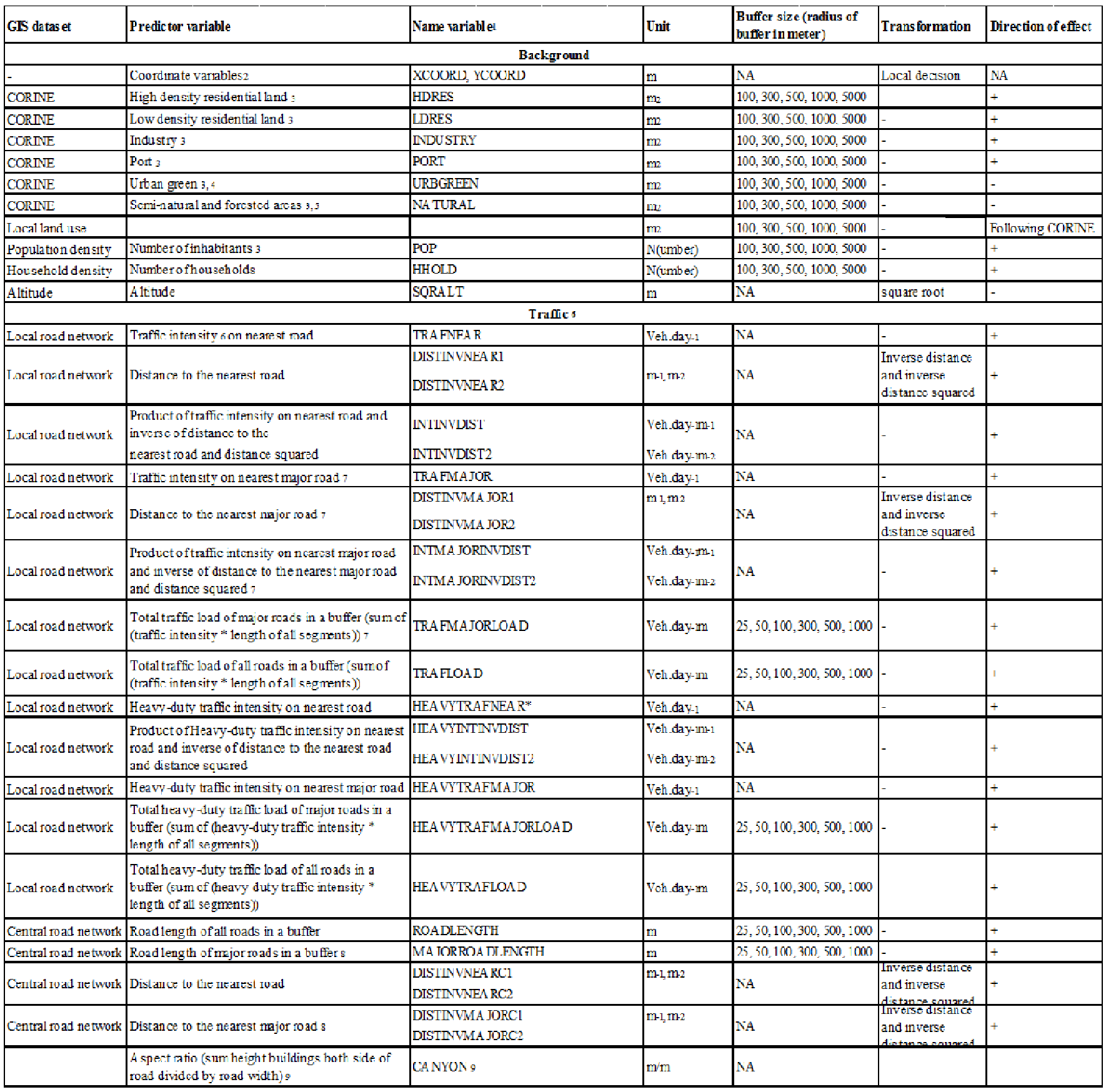


a)

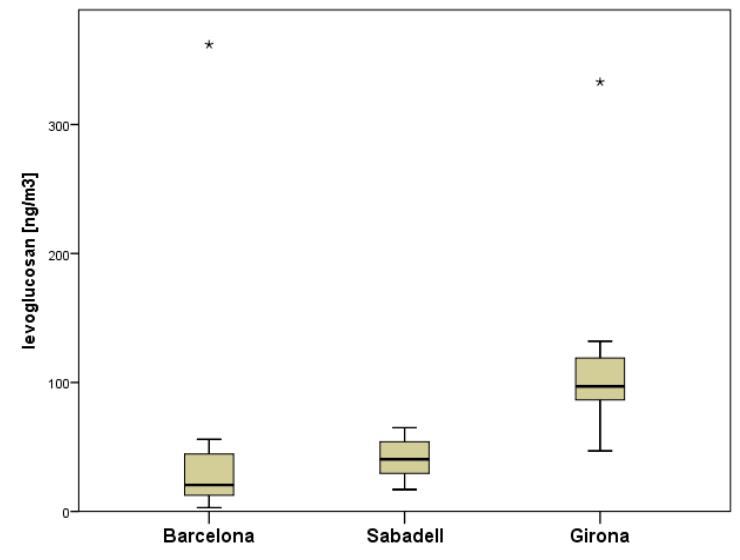

b)

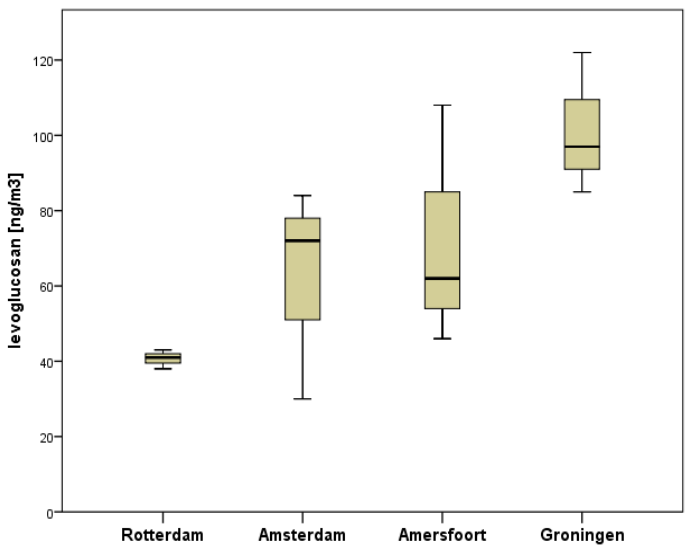

Figure S1. Distribution of the adjusted year average concentration of levoglucosan within study areas. Median, 25th and 75th percentiles are shown in the box, whiskers indicate 10th and 90th percentiles and individual outliers are shown. a) Catalonia, from south to north b) The Netherlands, from west to east.

Table S2: List of components used for temporal correction of levoglucosan with median Pearson temporal correlation (r)

\begin{tabular}{lll}
\hline Study area & Component & median $\mathrm{r}$ \\
\hline Oslo & PM2.5abs & 0.987 \\
Netherlands & NOx & 0.916 \\
Munich/Augsburg & NOx & 0.829 \\
Catalonia & NOx & 0.980 \\
\hline
\end{tabular}

$\mathrm{r}$ is the correlation between measurements of levolglucosan at a measurement site and the standard component measured at the reference site (e.g. $\mathrm{PM}_{2.5}$ absorbance for Oslo). Correlations are calculated per site and thus reflect the temporal correlation. The median of site-specific individual correlation coefficients are calculated and presented in the table.

Table S3: Pearson correlation (r) between unadjusted and ratio-adjusted concentrations of levoglucosan

\begin{tabular}{lc}
\hline Study area & $\mathrm{r}$ \\
\hline Oslo & 0.97 \\
Netherlands & 0.94 \\
Munich/Augsburg & 0.94 \\
Catalonia & 0.93 \\
\hline
\end{tabular}


Table S4. Difference of levoglucosan annual concentrations between site types (ratios RB/UB and S/UB)

\begin{tabular}{ll|cc}
\hline Study area & $\mathrm{n}$ & $\mathrm{RB} / \mathrm{UB}$ & $\mathrm{S} / \mathrm{UB}$ \\
\hline Oslo & 19 & 0.15 & 0.99 \\
Netherlands & 16 & 1.37 & 1.46 \\
Munich/Augsburg & 20 & 1.39 & 1.04 \\
Catalonia & 40 & $2.63^{*}$ & 1.19 \\
\hline
\end{tabular}

*Significant difference between site types with $p<0.01$

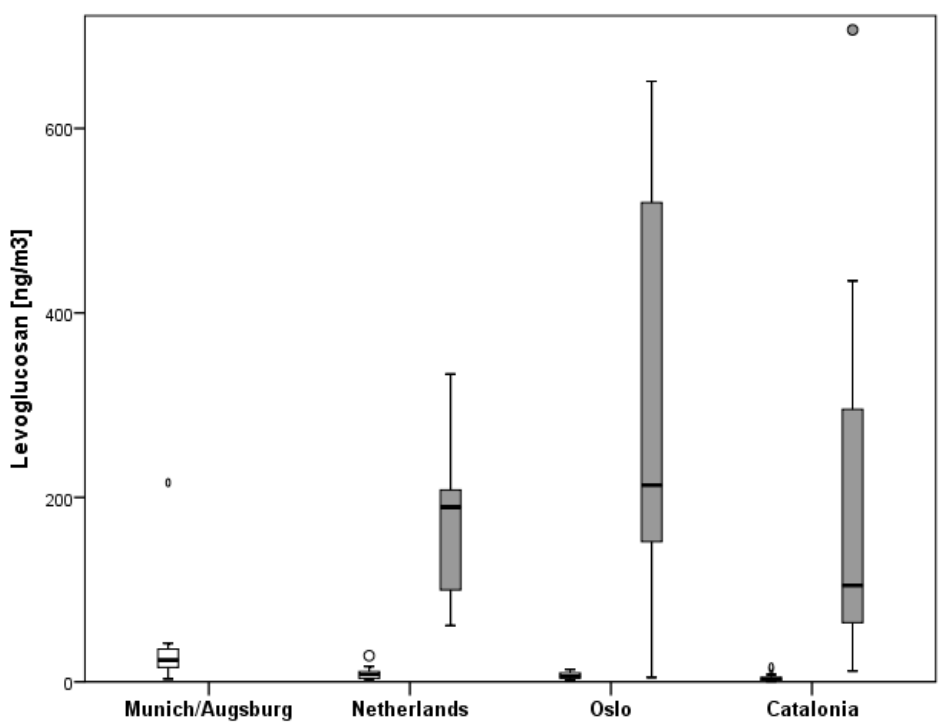

Figure S2. Seasonal differences of levoglucosan. White box - summer, grey box - winter

Table S5 Temporal correlation of levoglucosan with other components (median)

\begin{tabular}{|c|c|c|c|c|c|c|c|c|c|}
\hline & PM2.5 & PM2.5abs & NOX & $\mathrm{EC}$ & $\mathrm{OC}$ & $\Sigma \mathrm{PAH}$ & $\mathrm{B}[\mathrm{a}] \mathrm{P}$ & Shopanes/steranes & $\mathrm{K}$ \\
\hline Oslo & 0.931 & 0.984 & 0.997 & 0.999 & 0.927 & 0.999 & 0.998 & 0.963 & 0.909 \\
\hline Netherlands & 0.674 & 0.913 & 0.916 & 0.920 & 0.611 & 0.930 & 0.946 & 0.604 & 0.796 \\
\hline Munich/Augsburg & 0.980 & 0.662 & 0.996 & 0.773 & -0.016 & 0.996 & 0.997 & 0.760 & 0.997 \\
\hline Catalonia & 0.482 & 0.913 & 0.980 & 0.878 & 0.988 & 0.985 & 0.989 & 0.922 & 0.622 \\
\hline
\end{tabular}


Table S6 Median concentration ratios

\begin{tabular}{|c|c|c|c|c|c|c|c|}
\hline & Levo/PM2.5 & Levo/OC & levo/EC & levo/PAH & levo/K & K/levo & \\
\hline Oslo & 0.009 & 0.056 & 0.086 & 71.094 & 0.931 & 1.074 & Based on annual averages \\
\hline Netherlands & 0.004 & 0.039 & 0.048 & 52.885 & 0.575 & 1.739 & \\
\hline Munich/Augsburg & 0.007 & 0.040 & 0.075 & 77.663 & 0.377 & 2.653 & \\
\hline Catalonia & 0.003 & 0.017 & 0.019 & 36.963 & 0.247 & 4.043 & \\
\hline Oslo & 0.004 & 0.027 & 0.046 & 66.032 & 0.335 & 2.989 & All individual measurements \\
\hline Netherlands & 0.004 & 0.040 & 0.057 & 53.379 & 0.683 & 1.463 & \\
\hline Munich/Augsburg & 0.004 & 0.031 & 0.057 & 78.210 & 0.502 & 1.993 & \\
\hline Catalonia & 0.002 & 0.011 & 0.013 & 23.074 & 0.108 & 9.236 & \\
\hline Oslo & 0.027 & 0.153 & 0.173 & 72.397 & 2.832 & 0.353 & Cold season \\
\hline Netherlands & 0.006 & 0.066 & 0.082 & 53.379 & 0.929 & 1.077 & \\
\hline Munich/Augsburg & 0.011 & 0.108 & 0.137 & 78.118 & 1.186 & 0.843 & \\
\hline Catalonia & 0.004 & 0.024 & 0.028 & 46.171 & 0.363 & 2.754 & \\
\hline Oslo & 0.002 & 0.013 & 0.020 & 60.799 & 0.235 & 4.260 & Warm season \\
\hline Netherlands & 0.001 & 0.014 & 0.024 & 46.054 & 0.221 & 4.517 & \\
\hline Munich/Augsburg & 0.003 & 0.018 & 0.038 & 82.535 & 0.375 & 2.668 & \\
\hline Catalonia & 0.0004 & 0.003 & 0.003 & 7.644 & 0.034 & $\begin{array}{c}29.53 \\
2\end{array}$ & \\
\hline
\end{tabular}

